\title{
Unplanned left ventricular assist device insertion for dissecting intramyocardial hematoma during biventricular assist device explantation
}

\author{
Ioannis Dimarakis, PhD, FRCS C-Th, Tim Hayes, FRCA, and Rajamiyer Venkateswaran, FRCS C-Th, \\ Manchester, United Kingdom
}

\author{
From the North West Regional Heart Centre and Transplant Unit, University of South Manchester NHS Founda- \\ tion Trust, Wythenshawe Hospital, Manchester, United Kingdom. \\ Disclosures: Authors have nothing to disclose with regard to commercial support. \\ Received for publication Feb 23, 2017; revisions received June 30, 2017; accepted for publication July 20, 2017; \\ available ahead of print Sept 7, 2017. \\ Address for reprints: Ioannis Dimarakis, PhD, FRCS C-Th, Department of Cardiothoracic Surgery, Southmoor \\ Rd, Wythenshawe, Greater Manchester M23 9LT, United Kingdom (E-mail: jdimarakis@nhs.net). \\ J Thorac Cardiovasc Surg 2018;155:e63-5 \\ $0022-5223 / \$ 36.00$ \\ Copyright @ 2017 by The American Association for Thoracic Surgery \\ http://dx.doi.org/10.1016/j.jtcvs.2017.07.064
}

Video clip is available online.

A 35-year-old male patient presenting to his local emergency department with palpitations was found to be in atrial fibrillation with very fast ventricular response. Failing initial attempts of rate control, he sustained a ventricular fibrillation arrest requiring defibrillation. Urgent left heart catheterization demonstrated normal unobstructed coronary anatomy. By this point, the patient had entered a low cardiac output state with echocardiography confirming severe left ventricular systolic impairment. After initiation of inotropic support and insertion of an intra-aortic balloon pump, arrangements were made for his transfer to our unit.

On arrival, he was classified as Interagency Registry for Mechanically Assisted Circulatory Support level 1 with multiorgan failure and was immediately taken to the operating room for institution of venoarterial extracorporeal membrane oxygenation support. In view of the patient's hemodynamic instability, central extracorporeal membrane oxygenation was deployed with direct cannulation of the right atrial appendage and ascending aorta for venous drainage and arterial outflow, respectively. After an initial difficult period, he showed signs of stabilization allowing for conversion to a CentriMag (Levitronix LLC, Waltham, Mass) biventricular assist device. Temporary right ventricular assist device was established with the right atrium as the inflow and the main pulmonary artery as the outflow. Temporary left ventricular assist device was established via the left ventricular apical cannulation for inflow and the ascending aorta as outflow. Macroscopically, there was no thinning of the left ventricular wall or evidence of scarring or calcification. The inflow cannula was inserted into the apex of the left ventricle under echocardiographic

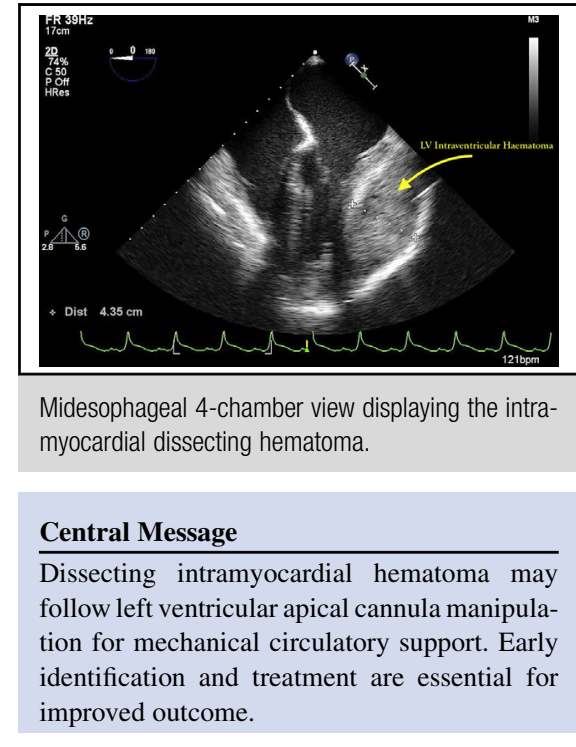

See Editorial Commentary page e67.

guidance for optimal positioning. All cannulae were introduced through separate upper abdominal stab wounds. Myocardial biopsies taken during the venoarterial extracorporeal membrane oxygenation implantation did not show any diagnostic features of the presumed diagnosis of viral myocarditis. Initial recovery included slow respiratory weaning and a prolonged period of hemofiltration. However, within 6 weeks he was alert, off renal support, and mobilizing in the intensive care unit.

Assessment at this stage indicated that adequate recovery of cardiac function had taken place to explant the biventricular support. In the operating room, support was weaned satisfactorily and we proceeded with explantation (Video 1). After 30 minutes of withdrawing support, the patient's blood pressure decreased to critical levels. It was not immediately apparent if this was related to impairment of his cardiac function or to bacteremia through explantation of the biventricular assist device cannulae. Transesophageal echocardiography demonstrated an expanding intramural dissection of the left ventricle (Figure 1, Video 2). The decision was made to implant a durable left ventricular assist device (HeartWare, HeartWare Inc, Framingham, Mass) as a bridge to recovery and decision. 


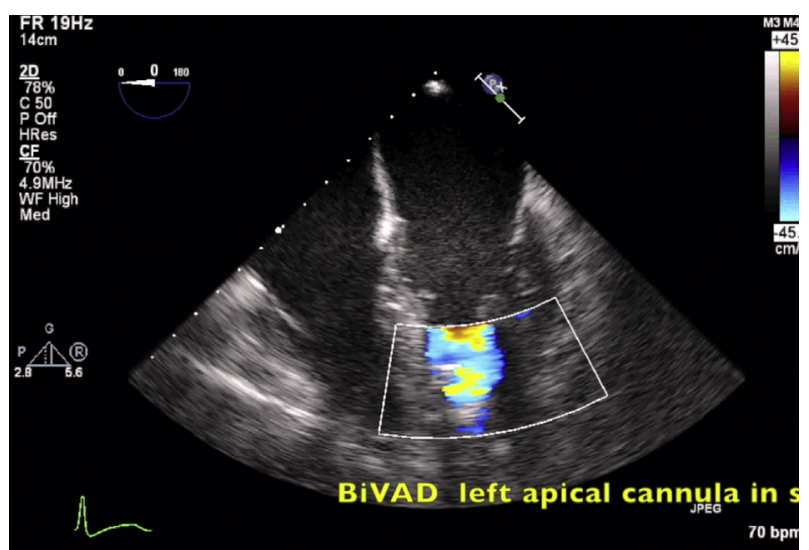

VIDEO 1. Midesophageal 4-chamber view at $0^{\circ}$ multiplane angle displaying the intramyocardial dissecting hematoma. BiVAD, Biventricular assist device. Video available at: http://www.jtcvsonline.org/article/S00225223(17)31717-8/fulltext.

Histologic examination of myocardial tissue at the time of the implant showed myocyte hyperplasia, extensive necrosis, and severe fibrosis, consistent with myocardial infarction.

During the course of the patient's follow-up in the ventricular assist device outpatient clinic, we became increasingly confident over the presence of myocardial recovery that might enable explantation of his device. Myocardial recovery assessment incorporating hemodynamic, echocardiographic, and cardiopulmonary exercise testing fulfilled all of the criteria as set out by the Berlin and Harefield protocols for explantation of the left ventricular assist device ${ }^{1,2}$ (Table 1). By this point, the intramural hematoma had completely resolved on echocardiography. Sixteen months after implantation, the patient underwent elective decommissioning of the left ventricular assist device via a minimally invasive approach. He subsequently required a primary prevention implantable cardioverter-defibrillator for easily inducible ventricular fibrillation. One year after, he remains clinically well and has returned to full-time employment.

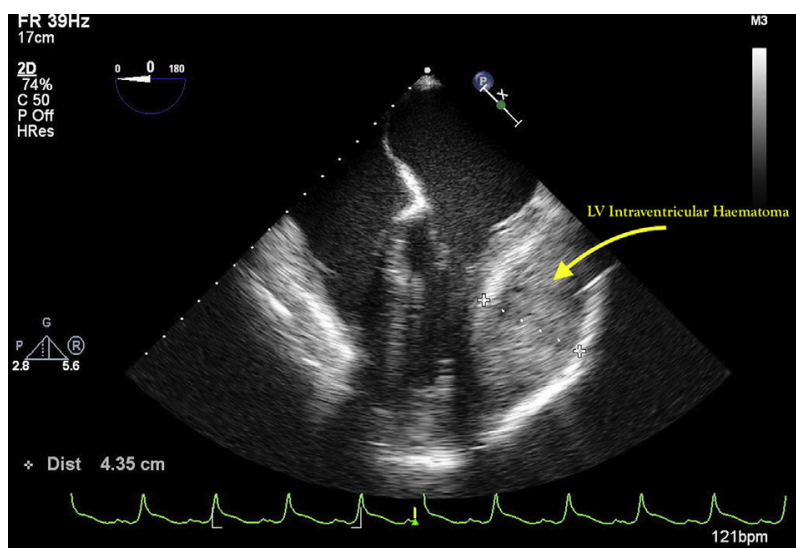

FIGURE 1. Midesophageal 4-chamber view at $0^{\circ}$ multiplane angle displaying the intramyocardial dissecting hematoma. $L V$, Left ventricular.

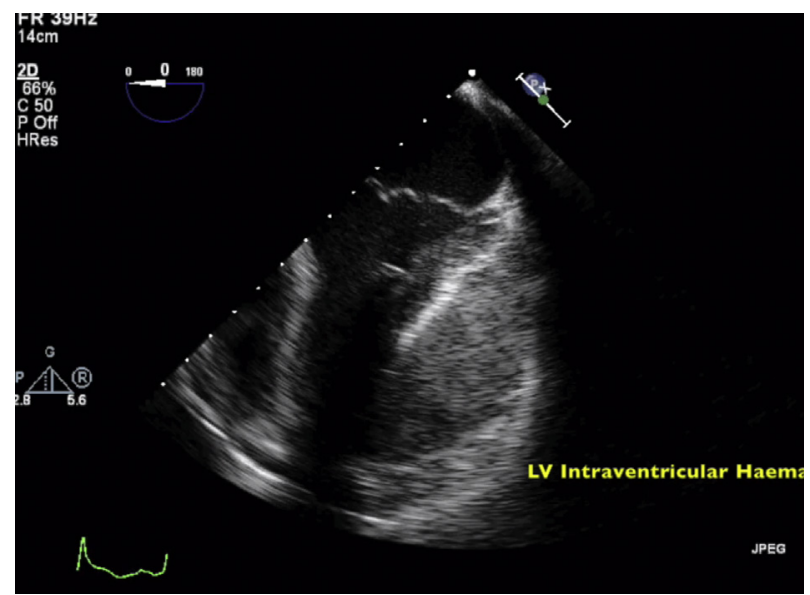

VIDEO 2. Midesophageal 4-chamber view at $0^{\circ}$ multiplane angle with the temporary left apical cannula in situ. $L V$, Left ventricular. Video available at: http://www.jtcvsonline.org/article/S0022-5223(17)31717-8/fulltext.

Intramyocardial dissecting hematoma has been described as a subacute cardiac rupture contained within the myocardial wall that develops along naturally occurring dissection planes between the spiral muscles of the ventricle. ${ }^{3,4}$ Myocardial infarction, chest trauma, and surgery all have been associated with the development of intramyocardial dissecting hematoma. Echocardiographic surveillance of an intramyocardial dissecting hematoma documented the potential to progress to left ventricular free wall rupture and pseudoaneurysm. ${ }^{5}$ Myocardial trauma during left ventricular apical cannula manipulation and subsequent removal were possibly the instigating factors for the formation of an intramyocardial dissecting hematoma in our case. In view of the non-flow-limiting coronary arterial vasculature, we hypothesize that unlike a scarred ventricle with reduced vascularity, vascular myocardial tissue might continue bleeding with subsequent hematoma formation. We can only

TABLE 1. Data from right heart catheterization, echocardiography, and cardiopulmonary exercise testing at full and minimal left ventricular assist device flow

\begin{tabular}{lll}
\hline \multicolumn{1}{c}{ Parameter } & $\mathbf{2 5 0 0} \mathbf{~ r p m}$ & \multicolumn{1}{c}{$\mathbf{1 8 0 0} \mathbf{~ r p m} *$} \\
\hline Hemodynamic & & \\
$\quad$ Cardiac output & $6.9 \mathrm{~L} / \mathrm{min}$ & $6.8 \mathrm{~L} / \mathrm{min}$ \\
$\quad$ Cardiac index & 3.1 & 3.0 \\
$\quad$ Mean pulmonary artery pressure & $13 \mathrm{~mm} \mathrm{Hg}$ & $13 \mathrm{~mm} \mathrm{Hg}$ \\
$\quad$ Wedge pressure & $7 \mathrm{~mm} \mathrm{Hg}$ & $9 \mathrm{~mm} \mathrm{Hg}$ \\
$\quad$ Mean arterial pressure & $82 \mathrm{~mm} \mathrm{Hg}$ & $82 \mathrm{~mm} \mathrm{Hg}$ \\
Echocardiographic & & \\
$\quad$ LVEDD & $4.6 \mathrm{~cm}$ & $5.1 \mathrm{~cm}$ \\
$\quad$ LV fractional shortening & $18 \%$ & $27.4 \%$ \\
Cardiopulmonary exercise testing & & \\
$\quad$ Peak oxygen consumption & & $21.4 \mathrm{~mL} / \mathrm{kg} / \mathrm{min}$ \\
$\quad$ Respiratory quotient & & 1.09 \\
\hline
\end{tabular}

$\overline{L V E D D}$, Left ventricular end-diastolic dimension; $L V$, left ventricular. *At the speed of $1800 \mathrm{rpm}$, there is no net flow across the HeartWare (HeartWare International, Inc, Framingham, Mass) continuous-flow device. 
prompt for meticulous hemostasis of the apical cannulation site. Intraoperative transesophageal echocardiography proved instrumental in the diagnosis of this pathology that necessitated the implantation of a durable left ventricular assist device to "rebridge" the patient to recovery. Although we did not find any similar case reported in the literature, in view of the increasing application of mechanical circulatory support, awareness of this clinical entity is important.

\section{References}

1. Dandel M, Weng Y, Siniawski H, Stepanenko A, Krabatsch T, Potapov E, et al. Heart failure reversal by ventricular unloading in patients with chronic cardiomyopathy: criteria for weaning from ventricular assist devices. Eur Heart J. 2011;32:1148-60

2. Birks EJ, George RS, Hedger M, Bahrami T, Wilton P, Bowles CT, et al Reversal of severe heart failure with a continuous-flow left ventricular assist device and pharmacological therapy: a prospective study. Circulation. 2011; 123:381-90.

3. Lewis AJ, Burchell HB, Titus JL. Clinical and pathologic features of postinfarction cardiac rupture. Am J Cardiol. 1969;23:43-53.

4. Pliam MB, Sternlieb JJ. Intramyocardial dissecting hematoma: an unusual form of subacute cardiac rupture. J Card Surg. 1993;8:628-37.

5. Harpaz D, Kriwisky M, Cohen AJ, Medalion B, Rozenman Y. Unusual form of cardiac rupture: sealed subacute left ventricular free wall rupture, evolving to intramyocardial dissecting hematoma and to pseudoaneurysm formation-a case report and review of the literature. J Am Soc Echocardiogr. 2001;14: 219-27. 